\title{
MENINAS PERALTAS: \\ FORMAÇÃO FEMININA EM LIVROS DE LITERATURA INFANTIL
}

MISCHIEVIOUS GIRLS:

FEMININE FORMATION IN CHILDREN'S LITERATURE BOOKS

\section{NIÑAS TRAVESAS: \\ FORMACIÓN FEMENINA EN LIBROS DE LITERATURA INFANTIL}

\section{Priscila Kaufmann Corrêa ${ }^{1}$ Maria do Carmo Martins ${ }^{2}$}

\section{RESUMO}

Este artigo é uma reflexão histórica sobre os livros infantis Que Amor de Criança!, da escritora francesa Condessa de Ségur e Clarita no Colégio, da escritora brasileira Maria Clarice Marinho Villac. Em Que Amor de Criança!, A Condessa de Ségur apresenta Giselle, uma menina mimada que não respeita os pais. Já Maria Clarice nos apresenta Clarita, criança peralta que é protegida pelos avós. Em ambos os casos as meninas são enviadas ao internato, tendo esta decisão consequências diferentes. Busca-se analisar o papel da escola na formação das meninas, a capacidade de legitimação social da escolarização pelo viés literário e refletir sobre o ensino da moral religiosa na formação feminina.

PALAVRAS-CHAVE: Literatura infantil. Escolarização. Ensino religioso. História Cultural.

\begin{abstract}
This paper aims a historical interpretation by the children's books What a lovely Child!, of the French writer Countess of Ségur and Clarita at School, of the Brazilian writer Clarice Maria Marinho Villac. In What a lovely Child!, the Countess of Ségur presents Giselle, a spoiled girl who does not respect her parents. Maria Clarice present us Clarita, a naughty child which is protected by her grandparents. In both cases the girls are sent to a boarding school for girls, and this decision leads to different consequences. The aim is to analyze the role of school education in the formation of girls, the social legitimation capacity of schooling by the literary bias and the reflection on the religious moral teaching in women's education.
\end{abstract}

KEYWORDS: Children's Literature. Schooling. Religious education. Cultural History.

\section{RESUMEN}

Este trabajo és una reflexión historica sobre los libros para niños Qué Amor de Niña!, de la escritora francesa Condesa de Ségur y Clarita en el Colegio, de la escritora brasileña Maria Clarice Marino Villac. La Condesa de Ségur presenta Giselle, una niña mimada que no respeta a sus padres. Maria Clarice nos presenta Clarita, una niña protegida por sus abuelos. En ambos casos, las niñas son enviadas a un internado, con consecuencias diferentes. El objetivo es analizar el papel de la educación en la formación de las niñas, la capacidad de legitimación social de la educación por el recorte literario y reflexionar sobre la enseñanza de la moral religiosa en la educación de mujeres.

PALABRAS-CLAVE: Literatura infantojuvenil. Enseñanza. Educación religiosa. Historia cultural.

\footnotetext{
${ }^{1}$ Mestra em Educação pela Universidade Estadual de Campinas, UNICAMP, Campinas, SP - Brasil. Professora de Educação Básica - Ensino Fundamental I da Prefeitura de Vinhedo, SP - Brasil. E-mail: prikco@ gmail.com. ${ }^{2}$ Doutora em Educação pela Universidade Estadual de Campinas, UNICAMP, Campinas, SP - Brasil. Professora do Departamento de Educação, Conhecimento, Linguagem e Arte da Universidade Estadual de Campinas, UNICAMP, Campinas, SP - Brasil. E-mail: carminha@unicamp.br.

Recebido em: 20/06/2015 - Aprovado em: 03/12/2015.
} 
Giselle fica vermelha; seus olhos brilham de raiva; ela está prestes a responder com ódio; mas não se atreveu. Saiu sem dizer uma palavra, e foi procurar sua babá. CONDESSA DE SÉGUR ${ }^{3}$

Clarita agora anda mais ajuizada, mas, mesmo assim, ainda tem ficado bastante de castigo, por não saber dominar o gênio. Clarita é muito geniosa e orgulhosa também. Por qualquer coisinha ela explode. Oh! Senhor! nesta idade, como os geniosos são esquentados!

\section{INTRODUÇÃO}

VIOLETA MARIA ${ }^{4}$

Giselle e Clarita são meninas geniosas e peraltas, que não reconhecem seus erros com facilidade. Personagens da literatura infantojuvenil, elas representam, literariamente, posturas de crianças conhecidas por suas autoras. As protagonistas dos livros Que Amor de Criança! e Clarita no Colégio, respectivamente, indicam que nem sempre as crianças se mostram voltadas para a pureza, carecendo de orientação dos adultos. A vivência em proximidade com a natureza também não se mostra suficiente, havendo a necessidade de outro espaço para que continuem sua formação. Além disso, os pais das meninas, nos dois livros, também precisam aprender a lidar com suas filhas, para que possam saber orientá-las.

Mas afinal, como se consegue educar crianças? Como construir a positiva imagem de que este papel cabe aos pais e também às outras instituições, tais como a escola? Este artigo faz uso da literatura infantojuvenil para compreender em que medida tais textos contribuem para a construção do imaginário social sobre a educação das meninas, em especial, no que se refere à educação escolar. Além disso, também auxilia nas reflexões acerca das relações entre pais e filhas, mediadas pela escola e tendo-a como espaço de coeducação, visão cada vez preponderante no contexto familiar.

Giselle e Clarita são meninas do século XIX e primeira metade do século XX, respectivamente, que foram enviadas por seus pais à escola por serem meninas travessas, após considerações que os esforços por parte dos progenitores para educarem-nas mostrou-se pouco produtivo. A experiência da escola provocou reações diferentes nas duas personagens e, como experiência de vida, refletiu, posteriormente, em suas vidas adultas, segundo o próprio enredo dos livros.

As duas publicações aqui analisadas não representam um reflexo fiel da realidade da época em que os livros foram escritos, mas são tomadas neste artigo de forma indiciária para pensarmos sobre elementos das relações familiares e, entre estes e as escolas frequentadas por filhos e filhas. Neste caso, a literatura traz as opiniões das escritoras sobre o lugar, o tempo e as atividades educativas, contribuindo para a construção de um imaginário social da escola. Naquele período, a escola já buscava abarcar um número cada vez maior de crianças e, pouco a pouco, passou a constituir o imaginário das pessoas, com suas crenças e ideias sobre ela.

${ }^{3}$ COMTESSE DE SÉGUR, Quel amour d'enfant!, 2010, p. 50.

${ }^{4}$ VIOLETA MARIA, Clarita no Colégio, 1945, p. 122. 
Ambas as escritoras, ou seja, a Condessa de Ségur e Maria Clarice Marinho Villac (que publicou sob o pseudônimo de Violeta Maria) dedicaram seus livros à infância e à juventude. As protagonistas das duas obras apresentam condutas consideradas inadequadas para a condição feminina da época em que se passam as estórias e, as escritoras apresentam possibilidades de lidar com as inadequações destas crianças, educando-as. Nos dois casos as meninas geniosas são enviadas ao internato, na tentativa de auxiliá-las a serem mais contidas e menos mimadas. E, nestas obras, a Condessa de Ségur e Maria Clarice Marinho Villac dialogam com as novas gerações de leitores e leitoras, orientando-as sobre em suas condutas.

Considerando que os livros apresentam uma finalidade educativa, dois conceitos são fundamentais para compor as reflexões neste ensaio. O primeiro deles é o de "forma escolar", termo cunhado pelos pesquisadores VINCENT, LAHIRE \& THIN (2001) que se refere à especificidade da relação entre um "mestre" (adulto) e um "aluno" (infante) na modernidade, como submetida a um conjunto de regras impessoais. Destacam que este processo é acompanhado de um espaço e da demarcação de um tempo especifico para a aprendizagem (um tempo da vida, o calendário anual, o horário diário). Os autores analisam como a forma escolar se relaciona com outras formas sociais, especialmente no que se refere à política e, tais relações políticas se aprofundam nas sociedades de cultura escrita, o que permite a emergência da forma escolar.

No período em que os livros foram publicados, ou seja, o final do século XIX e a primeira metade do século XX esta forma escolar já se consolidara, denotando uma preocupação crescente com a criança. A instituição escolar se apresenta, desde então, como uma possibilidade importante para a educação delas incluindo-se aí também as meninas. A Condessa de Ségur e Maria Clarice Marinho Villac, primeiro na condição de filhas, e posteriormente, na condição de mães, acompanharam estes movimentos e também se dedicaram a configurá-lo, na medida em que eram representantes dos extratos sociais que primeiramente se favoreceram da relação complementar de educação entre família e escola. Atuando diretamente na educação doméstica, elas estão atentas aos conteúdos e práticas legitimados pela escola e tratam disso em seus livros.

O outro referencial analítico importante, e que aqui se destaca, refere-se à concepção da “instituição imaginária da sociedade" proposta pelo filósofo Cornelius Castoriadis. Para este autor, a realidade de cada sociedade é uma criação, não havendo determinações já instituídas na realidade. A realidade sócio-histórica é composta por um estrato natural - isto é, as condições geográficas e biológicas - e condicionam a instituição à sociedade em particular. Cada sociedade cria suas instituições, a partir dos fatores naturais e, para Castoriadis, esta criação é parte do imaginário do inconsciente das pessoas - o imaginário radical -, mas é também o que constitui o imaginário social, que se expressa na e pela sociedade (SANTOS, 2010).

Dentro desta lógica, assim como a política, a religião, a ciência e a arte, a escola em sua função educativa, ganha enorme importância nas relações de poder. Como parte do imaginário social, ela é parte do imaginário das pessoas, que, mesmo sem terem frequentado o espaço escolar, conhecem as práticas que nele se realizam. Deste modo, a escola em seu caráter institucional, mas também por suas representações como constituinte das relações sociais, chega a ser concebida como espaço e tempo de educar as futuras gerações. 
Neste sentido é que se considera que as escritoras falam da instituição escolar a partir de suas experiências e apresentam também suas opiniões e crenças sobre ela. Em suas obras, se a escola é retratada como um espaço de punições e agressões, ela também poderia ser representada como espaço de formação de crianças, orientando-as para a vida adulta. Neste artigo, tendo a história da educação como referência, tecemos reflexões em torno dos livros destas escritoras que continuam marcando o diálogo intergeracional na contemporaneidade, mas o fazemos registrando o caráter coeducativo da experiência escolar em relação aos preceitos familiares da época.

\section{QUE AMOR DE CRIANÇA!}

O romance Que Amor de Criança! foi publicado em 1867 pela editora Hachette, que editou todos os 20 livros escritos pela Condessa de Ségur. A escritora iniciou sua carreira em 1856, quando já era avó. Este é um dos últimos romances que Sophie de Ségur viria a redigir. Em suas publicações ela traz diferentes histórias sobre a infância, demonstrando sua preocupação com a formação de crianças. Tal preocupação resulta em livros que possuem um caráter educativo marcante, que apresenta modelos de conduta desejáveis e rechaça as condutas inadequadas, tanto para os leitores infantis, quanto para seus pais.

A Condessa de Ségur foi aclamada pelos críticos literários como "Avó da nação", uma imagem que lhe dava credibilidade como escritora (HEYWOOD, 2008). Desde os primeiros trabalhos, Sophie de Ségur escrevia uma dedicatória a seus netos, procurando oferecer-lhes livros instrutivos. Sua experiência materna e como avó lhe permitia tratar da infância e oferecer orientações aos seus leitores. No caso de Que Amor de Criança!, ela escreve ao seu neto Louis de SégurLamoignon, ressaltando as qualidades do jovem em oposição aos defeitos de Giselle:

Querido filho, você é forte e generoso como um leão, gentil como um cordeiro e sábio como um anjo. Ao ler a história de Giselle, você deverá se poupar de imitá-la; em vez de cordeiro, é lobo, em vez de anjo, ela é diabólica. Então não tenha medo de ser comparado com esta menina impertinente. Você deve agradecer o seu pai e sua mãe, que te criaram bem, de forma que não se vê defeitos em você e boas qualidades destacam-se em toda a sua beleza. É assim que te julga a minha profunda afeição. Sua avó que te ama,

Condessa de Ségur, nascida Rostopchine. (COMTESSE DE SÉGUR, p. 4, Tradução nossa)

A escritora valoriza a educação no lar materno, como é possível identificar em outros livros seus. A postura dos pais, especialmente da mãe, se mostra fundamental para orientar os filhos. A educação escolar está presente em suas obras, tanto em casa, quanto no internato. No caso da protagonista de Que Amor de Criança!, o internato se torna uma opção desejável, pois os pais da menina não conseguem impor limites às vontades dela.

Giselle é a única filha do casal De Gerville, que a mima, em uma relação de temor pela perda do amor da filha. A falta de firmeza de seus pais faz com que ela não demonstre respeito por eles. A menina de dez anos de idade se mostra uma criança difícil de contentar, intrometendo-se em diversos assuntos e querendo realizar tudo da sua maneira. Seus pais, Victor e Léontine, não conseguem negar 
nada à criança. Giselle então manipula os pais e consegue tudo o que quer. Seu tio, Pierre Néri, irmão da $\mathrm{Sr}^{\mathrm{a}}$. De Gerville, busca refrear o comportamento de sua sobrinha, porém a irmã não compreende a severidade dele com a criança. Outros amigos do casal, como Sr. Tocambel e $\mathrm{Sr}^{\mathrm{a}}$. Monclair também procuram alertar Léontine sobre o comportamento de Giselle.

Em um determinado momento a $\mathrm{Sr}^{\mathrm{a}}$. De Gerville procura ser mais firme com sua filha e a menina sente a mudança. Ela até percebe que começa a respeitar mais a sua mãe, porém, quando contrariada, recorre ao Sr. De Gerville e este cede aos pedidos de Giselle. Ao longo da narrativa há vários momentos em que a criança se desentende com seus familiares, até que, com o auxílio da $\mathrm{Sr}^{\mathrm{a}}$. Monclair a menina deseja ser matriculada em um convento. A vida do internato se mostra interessante, pois Giselle consegue se relacionar bem com professoras e colegas.

É justamente o caráter impessoal da forma escolar, na relação estabelecida entre as professoras e esta aluna em especial, que conseguem, com as rotinas e regras do internato, conquistar o respeito e a atenção de Giselle. Apesar de inicialmente se recusar a frequentar o lugar, ela acaba se sentindo acolhida nele. Entretanto, após três anos no internato os pais sentem a falta de sua filha e lhe propõem uma vida de festas e luxos quando voltasse para casa. Logo Giselle se sente atraída por esta possibilidade e, em sua vida de bailes, conhece o Duque de Palma, com quem acaba se casando. Sua vida de casada não traz a felicidade que almejava e, com o falecimento de seu marido, ela decide casar com um amigo que a amava e a queria bem. A partir deste momento a jovem inicia um novo percurso, mostrando-se menos egoísta e interesseira. É a partir da vida adulta que Giselle muda sua conduta, aprendendo com sofrimento que nem tudo pode ser da maneira que deseja.

Entre seus diversos livros escritos para crianças a Condessa de Ségur apresentou diferentes formas de relação entre adultos e crianças. Em seus romances encontram-se madrastas terríveis que batem nas enteadas, mães que não conseguem orientar corretamente seus filhos e adultos que batem em crianças e mulheres. Até mesmo animais são bastante maltratados em suas publicações. Com o livro Que Amor de Criança! a escritora apresenta uma relação entre pais e filhos que se mostra perniciosa à formação das crianças. $\mathrm{O}$ romance apresenta pais que não conseguem construir uma relação baseada no respeito com sua filha e, se estes pais não chegam a agredir fisicamente a criança, eles também não conseguem recusar nada a ela, negligenciando os limites.

Por meio de um livro infantil a Condessa de Ségur dirige sua crítica aos pais que mimam excessivamente os seus filhos. Tal postura poderia resultar em consequências desastrosas na vida adulta, como a escritora apresenta na biografia de Giselle. Além disso, há também uma defesa da instituição escolar, que se mostra adequada para crianças como Giselle, que necessitam de limites. Desta maneira, a escritora também auxilia na construção do imaginário social, como uma criação que permeia o imaginário das pessoas e que é consolidada socialmente.

É interessante notar que este é um dos poucos romances em que a Condessa de Ségur apresenta um espaço de educação escolar voltado para a formação feminina. Em geral, a escritora aborda o tema da educação das meninas no âmbito doméstico. Em As Meninas Exemplares, por exemplo, Camila, Madalena, Margarida e Sofia, têm rotinas de estudos e exercícios em sua casa, com suas mães, mas dentro de preceitos escolares (DUFOUR, 2008). Tais nuances da formação 
infantil a escritora consegue apresentar ao longo de sua obra, demarcando espaços e práticas distintas, mas correlacionadas.

No livro, Giselle não consegue alterar sua conduta ao passar um curto período no convento. A escritora não descreve como ela vivenciou sua experiência escolar, mas sinaliza que esta era uma tendência entre a aristocracia francesa, que ela mesma conhecia bem como ambiente social. Seus filhos estudaram em internatos, mas suas filhas estudaram em casa e suas netas provavelmente tiveram experiências educativas diferenciadas, que poderiam incluir a educação escolar. O livro mostra, entretanto, que o internato acabava por ser uma alternativa para a educação de meninas e um recurso para os pais que não conseguiam lidar com os seus filhos e orientá-los de forma adequada.

Esta mesma situação também é vivenciada pelos pais de Clarita, que é uma menina travessa e geniosa, que inventa brincadeiras nas fazendas do interior paulista.

\section{CLARITA NO COLÉGIO}

Clarita é o nome da protagonista do livro Clarita no Colégio, de Violeta Maria (pseudônimo de Maria Clarice Marinho Villac) e que relata sua vida no internato e alguns acontecimentos com seus familiares. O livro traz a sequência de Clarita da Pá virada, que apresenta as brincadeiras e peripécias de Clarita nas fazendas de seus avós maternos. O Coronel Totó tinha fazendas, nas quais se plantava café e criava gado. $\mathrm{O}$ avô da autora também era dono de terras em Itu, além de ser um político influente na cidade. Os livros que escreveu trazem os relatos da infância da escritora, em sua vida nas fazendas e residências da família e, também, seu percurso escolar.

Os livros de Maria Clarice apresentam algumas peculiaridades com relação à produção literária destinada ao público infantil, que começava a ganhar forças no Brasil nas décadas de 1920 e 1930. Seus livros são de cunho autobiográfico e o tom de sua obra é de nostalgia, rememorando com saudades um passado agradável, mas também perpassado por perdas de entes queridos.

A crítica de literatura infantil Nelly Novaes Coelho (1991) esclarece que nas décadas de 1930 e 1940 a produção literária para o público infantil privilegiava as informações úteis e elementos para a formação cívica em detrimento do nível literário das obras, que perdiam muito em beleza. Sobre a produção deste período, ela ainda salienta o antagonismo existente entre a literatura de cunho realista e aquela mais fantasiosa, que estimula a imaginação, presente na obra de Monteiro Lobato, por exemplo.

As estudiosas Marisa Lajolo e Regina Zilberman (1993) destacam a tônica nacionalista destas obras, que permanece nas décadas de 1940 e 1950, ao lado de uma tentativa de afastamento da vulgarização e da cultura popular. Além disso, os espaços explorados pela literatura infantil neste período se dividem entre o meio rural, que representa o passado e a tradição, e o meio urbano, sinônimo do progresso e do desenvolvimento que o país buscava alcançar, tal como se afigurava entre os setores dominantes da sociedade à época (ibidem).

Maria Clarice Villac, como representante deste grupo dominante, também traz à tona, em sua obra, as relações entre sua família e os criados, muitos deles descendentes de escravos que, mesmo após a abolição, acabaram trabalhando para o seu avô. A autora mostra o quanto estes criados eram 
gratos e servis, como se estas fossem características "naturais" da raça negra. Em suas publicações a escritora não questiona o mundo dos adultos, nem mesmo a relação com estes trabalhadores, que acabam sendo considerados membros da família, pois cuidam das crianças e permanecem por muito tempo trabalhando para ela. No livro Clarita no Colégio, por exemplo, a própria babá de Clarita, além de cuidar da menina e seus irmãos, acaba por dedicar-se à criação dos filhos da protagonista, como o leitor vem a saber nas últimas páginas da obra (VIOLETA MARIA, 1945).

O livro apresenta características desta grande família, que engloba familiares e criados, convivendo em um mesmo lugar, mas tendo cada qual o seu papel social, de forma clara e hierarquizada. Porém, mesmo não apresentado críticas a estas relações, nota-se o quanto Clarita é uma menina travessa, que não se enquadra facilmente nos padrões de obediência feminina esperados pelos adultos.

Em Clarita da Pá virada, outro livro da autora, ela reconta suas peraltices na Fazenda de Pitanga, lugar em que passa as férias com sua mãe e seus irmãos. Seus avós, Sinhara e Coronel Totó têm muito filhos, alguns com idade próxima à de Clarita, como é o caso de Docarmo e Marina. Na fazenda as crianças observam as mulheres em seus afazeres domésticos, brincam em casinhas construídas para elas. Também se divertem na casa dos avós em São Paulo, importunando os adultos e até se arriscando no telhado da casa. A menina também chega a frequentar a escola, aprendendo elementos do catecismo, a leitura e a escrita, porém o ingresso definitivo no universo escolar se dá no final deste livro, quando Clarita, portando seu enxoval, toma o trem para Campinas, cidade de sua nova escola.

Os livros de Maria Clarice Marinho Villac apresentam o mundo rural por meio das fazendas da família, mas também apresenta o mundo urbano, com o internato situado em Campinas e com a casa situada em São Paulo. A circulação dos personagens entre cenários do campo e da cidade está presente nos livros. O pai de Clarita, como engenheiro, representa a vida urbana, levando a tecnologia da eletricidade para o interior do estado de São Paulo.

A obra Clarita no Colégio, que nos interessa de forma direta neste artigo, traz as vivências da menina no colégio interno da cidade, no qual as meninas e jovens deveriam se dedicar inteiramente aos estudos e ao seu aperfeiçoamento espiritual. Assim como o romance Que Amor de Criança!, o livro de Maria Clarice possui um prefácio, que consiste em uma carta de Maria José Dupré, escritora de livros como Éramos seis e A Ilha perdida. A Sra . Leandro Dupré (como era conhecida) ressalta a qualidade moral dos livros de Maria Clarice Marinho Villac.

Além disso, são livros de uma moral sã, que inspiram sentimentos profundamente religiosos e só podem fazer bem e auxiliar a formação do caráter de qualquer criança. Constituirão recurso precioso para pais e educadores cônscios das suas responsabilidades de educar e divertir. (DUPRÉ apud VIOLETA MARIA, sem data, p. 9).

A carta de uma famosa escritora do público infantojuvenil reconhecendo a boa qualidade dos livros de Maria Clarice é um bom indicativo para os pais e outros adultos que adquirem os livros da autora como leitura para crianças. Desta maneira, a carta de Maria José Dupré convida para uma leitura prazerosa e de moral considerada adequada aos pequenos leitores e leitoras. 
Clarita é uma menina geniosa e travessa, contudo, ela não comete ações com a intenção de magoar e machucar os outros, como Giselle. Clarita gosta de provocar e zombar dos outros, mas acaba se arrependendo de seus erros quando os adultos a alertam sobre eles. Quando passa seus dias na fazenda Pitanga, os pais de Clarita dificilmente podem tomar uma atitude mais incisiva sobre a filha, pois os avós, Dona Sinhara e Coronel Totó, protegem a criança e lhe dão liberdade para agir como desejar.

Entretanto, em alguns momentos os pais encontram maior possibilidade de punir a filha e o Sr. Azevedo recorre a uma escova de cerdas duras para bater em Clarita:

[...] e o papai pega então a escova, e... Nossa, fechem os olhos, tapem os ouvidos, para não verem, nem ouvirem...

Coitada de Clarita! Mas Clarita mereceu! Quem mandou ela ser desobediente? (VIOLETA MARIA, 1939, p. 132)

A própria escritora reconhece que deveria ser castigada, mas tais punições não se mostram eficientes para conter o comportamento desobediente de Clarita. Assim, diante da dificuldade de orientar e disciplinar a criança, os pais matriculam Clarita e sua irmã Nenete em um colégio interno para meninas. O colégio realmente existe até hoje, na cidade de Campinas, sendo conhecido como Colégio Progresso Campineiro.

A rotina do colégio não se mostra fácil, pois Clarita precisa aprender a controlar seus impulsos e adequar-se às regras do internato. A protagonista vivencia o cotidiano do internato, que aparenta ser um espaço agradável, mas ao mesmo tempo regrado, vigilante e controlador dos movimentos das alunas. É neste espaço que a menina muito geniosa e travessa aprende a controlar seus movimentos e vontades.

Maria Clarice Marinho Villac frequentou a escola no período de 1914 a 1920, época em que poucas meninas de sua idade podiam ingressar em tal instituição. A obra, contudo, é publicada na década de 1940, quando a escolarização se expandia no Brasil e era vista como necessária tanto para meninas, quanto para meninos. O livro deveria, pois, circular entre crianças que frequentassem o espaço escolar e assim elas poderiam tirar um aprendizado considerado valioso para suas próprias vidas. Neste aspecto é interessante notar como a literatura infantil se vincula não somente à concepção de infância, isto é, de um público específico, diferente do adulto, mas de um leitor que se encontra em um determinado espaço de socialização, que é a instituição escolar.

Ao longo do livro o imaginário social é o do reforço da importância da escola e, muitos dos parentes de Clarita passam a valorizar este lugar. A menina já não poderia ser educada apenas no ambiente doméstico, era necessário recorrer a profissionais que auxiliassem nesta tarefa. No Colégio Progresso a protagonista encontra na diretora, Dona Emília, um adulto que a aconselha e orienta. É neste lugar que a menina começa a refletir sobre suas ações e atitudes.

Também diferentemente de Giselle, Clarita é uma criança com disposição maior para mudar sua conduta. A vida no colégio altera efetivamente o comportamento da menina, que realiza várias tentativas para se conter. Com o auxílio da Diretora, Dona Emília e das professoras, a menina consegue refletir sobre seus erros. 
A vida escolar proporcionou uma mudança significativa na vida de Clarita, que reconhece o quanto este lugar e suas professoras contribuíram para sua formação. Neste percurso as práticas religiosas, como missas e retiros espirituais, são um elemento fundamental para que a menina busque se aperfeiçoar espiritualmente. Se durante a sua infância na fazenda Clarita não teve muito contato com elementos da religião, no colégio ela pôde realizar sua Primeira Comunhão junto com suas colegas e passou tomar parte das atividades religiosas. A religião católica deu um novo sentido à vida da criança, que passou a se preocupar mais com sua conduta.

Clarita tem, ao final do livro, uma vida adulta feliz, casando-se com um rapaz católico, com quem teve cinco filhos. Nos dois livros analisados (Que amor de Criança! e Clarita no Colégio) os finais trazem um desfecho feliz para ambas as protagonistas, mas no livro brasileiro a mudança acontece ao longo da trajetória escolar. Mais do que a Condessa de Ségur, Maria Clarice Marinho Villac atesta o quanto a vivência do internato, se bem conduzida por profissionais competentes, pode trazer bons frutos. Clarita se torna uma mulher mais contida e buscando um aperfeiçoamento espiritual constante.

Certamente, a distância temporal entre as autoras (e obras) e a consolidação da escola como instituição educativa permitem perceber a eficácia escolar pontuando o imaginário sobre a educação e o comportamento feminino, diferenciando Giselle e Clarita.

A Condessa de Ségur e Maria Clarice Marinho Villac tiveram acesso a uma formação diferenciada, no lar ou no colégio. Ambas eram filhas de famílias abastadas, que demonstraram uma preocupação com a formação de suas filhas. Tal formação não limitava aos trabalhos manuais e outras atividades domésticas, mas englobavam também a aprendizagem da leitura, da escrita e de línguas estrangeiras. Maria Clarice também teve aulas de física, química, biologia, matemática e desenho. Em cada uma das vivências a formação de cunho escolar era valorizada.

No caso de Sophie de Ségur, mesmo não estando entre as frequentadoras de uma escola na infância (porque sua mãe decidiu instruí-la em casa), quando iniciou sua atividade literária, mais madura e avó, a forma escolar já estava bastante difundida socialmente, sendo reconhecida a sua importância. O reconhecimento da cultura escrita, outro referencial importante para a consolidação da forma escolar, permeia a infância de ambas as escritoras, que, não por acaso, aprenderam a escrever e compor bons textos, com o auxílio da preceptora ou da mãe, ou das professoras do colégio. Sophie de Ségur e Maria Clarice souberam fazer uso destes conhecimentos e publicaram seus livros, tomando a escolarização e a valorização do imaginário social positivo sobre a escola por referências nestas duas obras.

Além disso, elas puderam publicar suas obras devido à efervescência do mercado editorial. $\mathrm{Na}$ França as editoras floresceram e se expandiram, como foi o caso da Hachette, que teve por muito tempo o monopólio da venda de publicações nas estações de trem (PARINET, 1993). As relações entre o editor e seus escritores já era mais formalizada. A Condessa de Ségur que trocava cartas com o editor Louis Hachette e também com Émile Templier, com os quais discutia os pagamentos e a censura a trechos de seus textos (HEYWOOD, 2008). Diversas vezes a escritora se desentendeu com seus editores, especialmente no que se refere às alterações realizadas em seus textos e à escolha dos 
ilustradores. Sophie de Ségur não deixava de questionar as interferências em seus escritos, porém muitas vezes acabava permitindo que fossem realizadas.

No caso do Brasil tal fenômeno estava mais consolidado no século XX. Maria Clarice Marinho pagou para ter suas obras impressas, uma vez que tinha dinheiro para investir nesta tarefa e que mostra seu empenho em conseguir entrar no mercado editorial. Neste caso, não há censuras ou cortes em seus trabalhos, havendo, inclusive, uma crítica favorável aos seus escritos. Ela recebeu uma homenagem da Biblioteca Infantil de São Paulo em 1959 e em 1979 foi eleita Membro Honorário da Academia de Literatura Infantil e Juvenil, como reconhecimento por sua contribuição à literatura infantil.

\section{REFLEXÕES SOBRE O ESPAÇO ESCOLAR}

A partir das experiências de vida da infância e da maternidade, as escritoras reuniram elementos para compor suas narrativas às crianças e jovens, indicando caminhos e possibilidades. Como já assinalado, há, nos 2 livros analisados, uma ênfase especial sobre a escola, conhecida por seu leitores, frequentadores deste espaço. Nos livros de ambas as escritoras, uma defesa da instituição escolar é expressa, bem como a consolidação da forma escolar e do predomínio da cultura escrita também fica evidente nas duas publicações. A literatura de ambas as escritoras mantém a (re)produção deste imaginário, que cada vez mais está presente na vida familiar, como parte integrante da infância.

Se, a partir do século XIX a escolarização se difunde de maneira mais intensa, tanto na França, quanto no Brasil, é também nessa época que se intensifica a compreensão sobre a criança um ser humano em formação, diferente do adulto. A instituição escolar se destina à criança e ao jovem, pois estes precisam conhecer o legado registrado pela humanidade.

A forma escolar, em sua dinâmica espaço-temporal, atenta às diferentes finalidades e atividades educativas e a propulsora de um conjunto de regras para a circulação neste lugar, como nos mostram Vincent, Lahire \& Thin (2001) compõe desde então o que se denomina educação. E é a eficácia desta forma escolar que garante a difusão da escolarização tanto entre as elites, quanto, paulatinamente, entre as classes populares. A escrita, por sua vez, permite o registro da cultura acumulada e é na escola, um espaço específico, distinto de outras práticas sociais, que estes saberes são difundidos. Neste lugar o saber se separa das práticas sociais e cria suas próprias regras, as quais os alunos devem incorporar e obedecer.

As congregações religiosas tinham a sua forma de organização do ensino, como foi o caso das Escolas Cristãs e as Escolas Mútuas, ou mesmo a Companhia de Jesus, que elaborou com a Ratio Studiorum (JULIA, 2001). Desde o século XV estes grupos de religiosos se preocupavam com o ensino e no século XIX a escola, tanto de cunho religioso, quanto laica ganhava espaço, juntamente com outras discussões em torno da criança e sua formação.

$\mathrm{Na}$ França este tipo de organização escolar, entre outras, estava presente em vários lugares do país. Sob o comando do ministro da educação, Victor Duruy, a partir de 1863, foi iniciada uma série 
de reformas para ampliar o acesso à educação. Na segunda metade do século XIX começou a se fortalecer um movimento em torno na proteção da criança contra a agressão dos pais (HEYWOOD, 2008). Alguns religiosos, como o Bispo Dupanloup, e mesmo o manual das Escolas Cristãs, condenavam a punição corporal, que era frequente entre as famílias e até mesmo nos internatos franceses. Foi o Bispo Dupanloup que também reforçou a presença da Igreja católica, especialmente no que se refere à formação feminina (PAPIEAU, 1999). A ênfase da formação das meninas recaía especialmente na piedade, para que pudessem se tornar mães aptas para formar seus filhos nos preceitos morais da Igreja.

A Condessa de Ségur era favorável ao catolicismo ultramontano e as questões da piedade e caridade estão presentes em seus livros. Ela era consciente dos castigos físicos presentes nos internatos e encarava a escola de forma pouco positiva em seus livros. Em geral, seus personagens sofrem neste lugar, que é visto como último recurso para os pais enviarem seus filhos, um meio aceitável para combater algum tipo de delinquência, o que a coloca em um lugar que demonstra ainda algum estranhamento quanto à instituição e seus métodos.

No romance Que Amor de Criança!, a menina apresenta um comportamento pouco desejável, próximo da delinquência, pois além de mentir, chega a roubar. Logo no começo do livro ela se indispõe com seus tios e destrói as flores que seus primos Georges e Isabelle estavam utilizando para preparar um buquê para sua mãe. O tio, Sr. Néri, prende a menina em seu escritório e só a deixa sair quando a babá da criança a vem buscar.

Ao retornar à casa Giselle se queixa de seu tio e conta o quanto foi humilhada por ele. Sua mãe, Léontine, se compadece da criança e decide ter uma conversa séria com seu irmão. Antes de fazê-lo, entretanto, um velho amigo, Sr. Tocambel, entra na casa e conversa com a mãe e a filha. O amigo assegura a Léontine que Sr. Neri não surrou a menina e quis que esta refletisse sobre seu erro. A menina antipatiza com o Sr. Tocambel, pois percebe que não consegue manipular sua mãe na presença dele.

Giselle chega ao ponto de roubar as botas do Sr. Tocambel que ele ganhou em uma loteria. Sr. Tocambel, sabendo do roubo, resolveu levar um falso sargento que ameaçou prender Giselle, caso ela não devolvesse as botas. A menina ficou assustada com a presença do suposto militar e entregou as botas ao velho amigo da família. O Sr. Tocambel contou sobre o incidente à mãe de Giselle, que não gostou da medida tomada por ele. Léontine logo imaginou que o marido poderia comprar novas botas, mas a $\mathrm{Sr}^{\mathrm{a}}$. Monclair, amiga do casal, explica que a menina precisaria de uma punição e não de uma compensação pelo roubo.

Apesar disso, os pais a presenteiam e a Sra. Monclair reage, acuando-a. Ao final desse episódio, a menina arrepende-se, perde perdão à sua vítima (por pouco tempo ela consegue se controlar, mas logo apronta outras malcriações) e a $\mathrm{Sr}^{\mathrm{a}}$. Monclair passa então a insistir para que ela entre em um colégio interno, em um convento, após a menina haver assumido que a respeitava mais do que aos pais que sempre faziam todas as suas vontades.

A habilidosa senhora também argumenta que a criança logo seria enviada de volta para casa por ser mal-educada e teimosa. Ao ser desafiada, a menina decide que vai entrar em um convento e 
pede a permissão de seus pais. Estes ficam tristes com a determinação da menina, mas aceitam. A $\mathrm{Sr}^{\mathrm{a}}$. Monclair acompanha Giselle nas compras do enxoval e a menina logo se sente bem no colégio, no qual permanece por três anos, apesar da relutância dos pais em deixá-la ir.

Em Que Amor de Criança!, a autora reconhece que, por vezes, a disciplina imposta por freiras e professoras, em um espaço diferente do lar materno, pode ser uma alternativa corretiva. Como uma pequena "delinquente", Giselle precisa ser enviada ao convento para ser disciplinada. Ela descobre que neste lugar as professoras a tratam com respeito e a aconselham, diferentemente do que acontece em sua própria casa. Castigos físicos não são mencionados neste livro. A menina escolhe o Convento de Nossa Senhora das Vitórias, instituição que até hoje funciona como estabelecimento escolar na França. Apesar do período passado no convento não se mostrar efetivo na formação da menina, ela inicialmente se sente acolhida neste lugar. A formação moral oferecida pelo internato se mostra eficiente até certo ponto e a menina retorna à casa dos pais mais contida.

O romance é voltado para a relação social entre professores e estudantes e as finalidades educativas, porém não explicita a organização interna do convento, com seus horários e regras, apesar de sabermos que existem. O aspecto moral certamente estava presente no currículo e nas práticas escolares. Em uma passagem, a madre superiora afirma que, sabendo do caso de Giselle, decidiu ser firme e doce com ela. A relação específica entre professoras, madres e alunas, aparentemente traria bons resultados para a formação de Giselle. Nota-se que há a necessidade de construir uma relação de rigor e disciplina com as alunas, entretanto, não se pode perder de vista o afeto com elas. Para a Condessa de Ségur, é preciso encontrar um equilíbrio entre o rigor e o carinho no trato com as crianças (HEYWOOD, 2008).

Neste romance não é o convento que provocará a mudança na conduta da protagonista. Somente na vida adulta Giselle compreende que bailes, luxos e caprichos não seriam garantia de felicidade e satisfação. A Condessa de Ségur mais uma vez apresenta uma personagem cujas experiências e histórias de vida são, no conjunto, elementos que ajudam a ponderar sobre as consequências de uma formação inadequada durante a infância. Em seu livro ela critica a conduta dos pais que ela também observara em sua vivência na aristocracia francesa. Além disso, sem frequentar uma escola, ela conhecia seu funcionamento e um aspecto fundamental da organização desta instituição consiste no estabelecimento de regras impessoais, a serem respeitadas pelos alunos. Este tipo de disciplina possibilita a aprendizagem de uma forma de exercício do poder. A criança obedece às regras, que estão acima dos adultos, mas que eles orientam e controlam (VINCENT, LAHIRE, THIN, 2001). Existe um poder superior, apresentado por meio de regulamentos, que norteiam a rotina escolar. Para a Condessa de Ségur, a disciplina é necessária na formação das crianças e as regras são importantes neste sentido.

As regras impessoais também estão bastante presentes em Clarita no Colégio. Ao frequentar o colégio, Clarita logo percebe que não pode fazer tudo de acordo com sua vontade. Há determinados tipos de conduta que são esperadas no espaço da escola e que precisam ser respeitadas. Nesta publicação a vivência escolar é mais esmiuçada e a autora apresenta diversos elementos do funcionamento do internato. O colégio fundado para atender as filhas dos comerciantes e proprietários de terras foi uma iniciativa dos parentes destas meninas, que buscavam uma formação 
escolar para elas. Mais uma vez a escola se apresenta como uma instituição imaginária, que permeia diferentes segmentos da sociedade.

No Brasil a expansão da escolarização também aconteceu entre o século XIX e especialmente ao longo do século XX. Vidal e Faria Filho (2000) traçam um panorama da organização das escolas primárias no país, que começou com instituições de improviso, que posteriormente se tornaram escolas-monumento, para depois serem escolas funcionais. Além das escolas públicas, também as instituições religiosas tiveram seu papel neste setor. Jesuítas, salesianos, maristas e tantas outras congregações criaram seus estabelecimentos escolares, atendendo diversas camadas da população, especialmente as mais abastadas.

Certamente este processo se deu de forma mais lenta no que se refere à escolarização das meninas, que, em geral, tinham uma formação voltada para as atividades domésticas e não tanto para a aquisição de conhecimentos.

Avanços em relação às reivindicações feministas sobre a educação para mulheres e o próprio reconhecimento dos homens de que elas precisavam ser educadas para poderem zelar pela formação moral de seus filhos, levaram à criação de escolas para meninas (ALMEIDA, 1998). Mais uma vez as congregações religiosas se dedicaram a esta função, mas havia também escolas laicas, que muitas vezes não abriam mão do ensino do catecismo ou do ensino religioso, assegurando a formação moral das meninas. Este foi o caso do Colégio Progresso Campineiro, instituição em que Maria Clarice estudou. A escola se pretendia laica e seu projeto educacional ganhou força com a presença de Dona Emília de Paiva Meira, que adotou muitas práticas religiosas, como a missa e retiros espirituais.

Além das matérias voltadas para as humanidades e ciências exatas, como matemática, biologia e química, as internas também tinham aulas de catecismo, religião e história sagrada (CORRÊA, 2010). Contudo, na medida em que o colégio adota os currículos oficiais - para assegurar a certificação de suas alunas - estas matérias voltadas para o ensino religioso já não ganhavam a mesma visibilidade, especialmente no ensino secundário, a fase final da formação das jovens. $\mathrm{O}$ ensino religioso era assegurado pelas práticas voltadas para a religião. As missas diárias, além de outros eventos religiosos, asseguravam a presença da religião católica na rotina da instituição.

Em Clarita no Colégio a narradora relata seu dia a dia no Colégio Progresso e suas traquinagens. Seu comportamento acabou merecendo alguns castigos e muitas conversas com Dona Emília, que emerge como figura central no esforço de tornar Clarita uma menina mais obediente. A diretora observa todas as meninas, ou é informada sobre a conduta de cada criança, sabendo aconselhar cada uma ou chamando sua atenção. Clarita precisou passar várias vezes pelo escritório da diretora, ouvindo seus sermões e permanecendo sentada no banquinho do escritório.

O Sistema Preventivo Salesiano estava presente no cotidiano da escola. Dona Emília tinha uma grande afinidade com a congregação salesiana de Campinas. Alguns padres salesianos rezavam missas no colégio e também eram padres-diretores das associações religiosas. A Congregação Salesiana foi criada por Dom Bosco na Itália e dedicava-se à formação de meninos órfãos. Dom Bosco mantinha um bom relacionamento com as crianças, tratando-as com carinho e bondade, sem abrir mão de regras para garantir uma boa convivência no grupo. 
O método preventivo se estrutura em traz pilares: Razão, Religião e Amorevolezza, que auxiliam o educando a atingir a sabedoria, a santidade e a saúde. $\mathrm{O}$ educador orienta o educando com bondade, vigiando-o em suas ações, para que ele se aperfeiçoe tanto no plano intelectual, quanto no espiritual (SANTOS, 2000). Graças ao método preventivo o aluno torna-se ciente das regras e assim evita transgredi-las. Com isso, o educador também não deve nunca fazer uso de castigos físicos, eventualmente podendo repreender o aluno. Neste sistema educativo o diretor é a figura central e a ele os demais professores e alunos se dirigem.

Dona Emília adotou muitos elementos deste método no Colégio Progresso, pois, no internato, todas as crianças e as professoras tinha conhecimento das regras e eram constantemente vigiadas para assegurar o cumprimento destas regras. Em alguns momentos os sermões e as conversas se mostravam necessárias para orientar as alunas.

A religião católica se mostrou um elemento bastante presente na moralização de Clarita, emergindo nos sermões de Dona Emília e também como um estímulo em prol do bom comportamento. Com suas colegas - todas elas de famílias abastadas da região - Clarita brinca e se diverte e também acaba cometendo alguns deslizes. Por meio de Dona Emília e dos professores, ela é orientada a se comportar, mas não consegue se conter. Logo no começo do livro Clarita se encontra de castigo, juntamente com Mimi e Sada, no refeitório. Dona Emília as observa durante todo o horário do recreio, enquanto as demais alunas estão brincando. Clarita, Sada e Mimi ficaram balançando seu banco no fundo da sala na aula de geografia de Dona Córa e acabaram sendo levadas para a diretoria.

Certa vez, quando Clarita e sua colega Mimi resolvem caçoar da aparência de uma professora nova, acabam sendo chamadas ao escritório de Dona Emília. Esta questiona cada criança individualmente sobre o que fizeram ao longo do dia até que se lembrem do momento em que zombaram da professora. A diretora chama a atenção sobre a postura das meninas, que se mostraram grosseiras. Clarita aos poucos reconhece seu erro e é obrigada a ficar sentada no banquinho do escritório de Dona Emília de castigo. O mesmo acontece com Mimi.

No internato Clarita já não pode mais se proteger sob os cuidados da avó. Se na fazenda ela podia escapar de castigos de seus pais, no colégio ela pode apenas contar com sua irmã e sua vontade de mudar sua conduta. O auxílio de Dona Emília e da professora de catecismo, Dona Amandina, permitem que Clarita se dedique mais à religião católica. Com a Primeira Comunhão e com a Crisma, Clarita se aproxima mais do sagrado e procura se conter mais.

Ao longo da narrativa Clarita também acaba perdendo a sua avó materna e sua mãe, sentindose mais solitária no internato. Dona Emília, a diretora que está sempre atenta aos movimentos e sentimentos de suas alunas, ganha maior importância na vida da menina, pois, apesar de não se mostrar muito afetuosa, ela orienta e conversa bastante com ela. Apesar do rigor com que impõe os castigos a Clarita, ela busca ajudar a menina a se conter e observa a sua conduta.

Outro fator importante para Clarita foi seu ingresso na Pia União das Filhas de Maria. A Pia União foi apenas uma das associações religiosas organizadas no Colégio Progresso e um dos 
requisitos para tomar parte nela era o bom comportamento. Deste grupo seleto podiam participar apenas as meninas mais virtuosas e obedientes, dignas de receberem a fita azul de associadas.

Dona Amandina muito aconselhou a protagonista da obra e a orientou para ser obediente e empenhada, a fim de que a menina pudesse ser aceita como Filha de Maria. Clarita quase colocara tudo a perder ao discutir com Dona Emília, que a alertava para não andar com uma determinada aluna. Clarita se arrependeu de seu acesso de raiva e desesperou-se diante da possibilidade de não ser aceita como Filha de Maria. Por intervenção de Dona Amandina, Clarita pôde ser aceita, significando o ritual de recepção das fitas como um momento glorioso em sua trajetória escolar.

O livro Clarita no Colégio permite perceber alguns dos elementos que comporiam o cotidiano do Colégio Progresso, emergindo aí também as práticas religiosas. O ingresso em uma associação religiosa significava um momento de destaque na vida escolar das meninas, sendo celebrado com grande pompa. Clarita recebeu a sua fita azul e seu livro da Pia União com os olhos repletos de lágrimas, emocionada de ser considerada filha de Maria.

Nota-se que, diferentemente de Giselle, Clarita encontrou na religião a vontade real de adotar uma postura diferente. A vida no internato mudou a vida da menina, que se tornou uma jovem mais contida. Maria Clarice mostra, em Clarita, uma menina peralta e geniosa, que se torna um exemplo para seus leitores, pois ela consegue se tornar uma mulher mais contida, sem necessariamente passar pelos mesmos sofrimentos que Giselle sofre com seu casamento fracassado com o Duque de Palma. A autora de Clarita no Colégio traz à tona a sua própria trajetória de vida como um modelo, descrevendo todas as suas dificuldades neste percurso.

As personagens Giselle e Clarita são crianças da elite, com experiências no internato, mas que a passagem pelo espaço escolar resultou diferente. O contato com a forma escolar está presente nos dois livros, alertando aos jovens leitores o quanto esta relação pode ser significativa na vida de uma criança. Se hoje a instituição escolar está consolidada na sociedade, permeando seu imaginário, os livros da Condessa de Ségur e de Maria Clarice Marinho Villac trazem à tona este lugar que se concretizava, perpassado opiniões divergentes, mas que já o reconheciam como efetivo. A escola foi se modificando, se recriando, emergindo de diferentes maneiras nas publicações das duas escritoras.

As obras de Sophie de Ségur e Maria Clarice convidam à reflexão acerca da escolarização e da formação moral das crianças. Em períodos diferentes elas trazem, em seus romances, a relação entre a moral e a religiosidade, que, nos dois casos, estão bastante ligados. A formação moral das meninas passa pela religião católica, mas, somente esta não é suficiente para alterar a conduta das meninas. Castigos físicos também não devem estar presentes no âmbito escolar, sendo essencial uma relação de respeito, baseada na disciplina e com certos gestos de carinho. A postura dos pais também é questionada nos dois livros, pois ambos os casais não conseguem impor sua autoridade perante suas filhas. Contudo, os pais de Clarita passam a estimular a frequentar o colégio, enquanto os pais de Giselle procuram dissuadi-la de lá permanecer.

Além disso, ambas as escritoras indicam que cabe aos adultos orientar e estar presentes na vida da criança. Pais que mimam e se mostram distantes das vivências das crianças não contribuem para a formação delas. Adultos firmes como a Sra. Monclair, no livro da Condessa de Ségur, e de 
Dona Emília, no livro de Maria Clarice Marinho Villac, mostram que não é apenas com mimos que se conquista o carinho e, especialmente, o respeito das crianças.

As publicações destas duas mulheres instigam a refletir sobre a relação entre a família e a escola e continuar buscando novas possibilidades interpretativas até os dias atuais. Sendo a escola e a família duas instituições atuais e em constante transformação, cabe continuar criando e recriando interpretações, análises e reflexões sobre elas e as relações que constroem. Nesse sentido, a fonte literária mostra-se especialmente rica em detalhes e instigante quanto à sua interpelação.

\section{REFERÊNCIAS}

ALMEIDA, Jane Soares de. Mulher e educação: a paixão pelo possível. São Paulo: UNESP, 1998. Disponível em: 〈http://goo.gl/JzQOT3 >. Acesso em: 20 jun. 2015, p. 119.

BEAUSSANT, Claudine. La comtesse de ségur ou l'enfance de l'art. Paris: Éd. R. Lafont, 1988.

CASTORIADIS, Cornelius. A instituição imaginária da sociedade. Rio de Janeiro: Paz e Terra, 1982.

COELHO, Nelly Novaes. Panorama histórico da literatura infantil juvenil. São Paulo: Ática, 1991, p. 241.

COMTESSE DE SÉGUR. Quel amour d'enfant!. Paris: Hachette, 2010.

CORREAA, Priscila Kaufmann. O ensino religioso no Colégio Progresso Campineiro: entre prescrições e práticas (1900 - 1937). 2010. 241 f. Dissertação (Mestrado em Educação) - Faculdade de Educação, Universidade Estadual de Campinas, Campinas, SP, 2010. Disponível em: < http://goo.gl/eZC7TU $>$. Acesso em: 20 jun. 2015, p. 46.

FARIA FILHO, Luciano Mendes de; VIDAL, Diana Gonçalves. Os tempo e espaços escolares no processo de institucionalização da escola primária no Brasil. Revista Brasileira de Educação, Rio de Janeiro, RJ, n. 14, p. 19-34. mai./ago. 2000. Disponível em: 〈http://goo.gl/62TSGv〉. Acesso em: 20 jun. 2015. ISSN 1809-449X.

HEYWOOD, Sophie. The Comtesse de Ségur: catholicism, children's literature, and the culture wars $^{\text {ee }}$ in nineteenth century France. 2008. 319 f. Tese (Doutorado em Filosofia da História) Universidade de Edinburgh, Reino Unido, 2008. Disponível em: < https://goo.gl/MqKrMN>. Acesso em: 20 jun. 2015, p. 51-166.

JULIA, Dominique. A cultura escolar como objeto histórico. Revista Brasileira de História da Educação, Rio de Janeiro, RJ, v. 01, p. 09-43. jan./jun. 2001. ISSN 1809-449X, p. 14.

LAJOLO, Marisa, ZILBERMAN, Regina. Um Brasil para crianças: para conhecer a literatura infantil brasileira. São Paulo: Global, 1993, p. 126-132.

PAPIEAU, Isabelle. La comtesse de ségur et la maltraitance des enfants. Paris: L'Harmattan, 1999, p. 77-85. 
PARINET, Elisabeth. Les bibliothèques de gare, un nouveau réseau pour le livre. Romantisme, 1993, vol. 23, n. 80, p. 95-106. 1993. Disponível em: 〈http://goo.gl/K1M1um>. Acesso em: 20 jun. 2015.

SANTOS, Helder Azevedo. O pensamento político de Cornelius Castoriadis. 2010. $78 \mathrm{f}$.

Dissertação (Mestrado em) - Universidade do Porto, 2010. Disponível em:

<https://goo.gl/noC1Ww>. Acesso em: 20 jun. 2015, p. 35.

SANTOS, Manuel Isaú Ponciano dos. Luz e sombras: internatos no Brasil. São Paulo: Salesiana Dom Bosco, 2000, p. 416.

VIOLETA MARIA. (Maria Clarice Marinho Villac). Clarita da pá virada São Paulo: Revista dos Tribunais, 1939.

VIOLETA MARIA. (Maria Clarice Marinho Villac). Clarita no colégio. São Paulo: Cristo-Rei, 1945.

VINCENT, Guy; LAHIRE, Bernard; THIN, Daniel. Sobre a história e a teoria da forma escolar. Educação em Revista, Belo Horizonte, MG, n. 33, p. 07-47. jun. 2001. Disponível em: <http://goo.gl/bH177o >. Acesso em: 20 jun. 2015. ISSN 1982-6621, p. 13-30.

\section{Como citar este documento:}

CORRÊA, Priscila Kaufmann; MARTINS, Maria do Carmo. Meninas peraltas: formação feminina em livros de literatura infantil. ETD - Educação Temática Digital, Campinas, SP, v. 18, n. 2, abr./jun. 2016. ISSN 1676-2592. Disponível em: <http://periodicos.sbu.unicamp.br/ojs/index.php/etd/article/view/8637338>. Acesso em: 04 jul. 2016. doi:http://dx.doi.org/10.20396/etd.v18i2.8637338. 